\title{
Evaluation of Perceived Stress in Family Members of Stroke Patients
}

\author{
Gayatri T. Batkulwar ${ }^{1}$, Gaurav C. Mhaske ${ }^{2}$ \\ ${ }^{1}$ Intern, MGM Institute of Physiotherapy Aurangabad. \\ ${ }^{2}$ M. P. T Neurology, Assistant Professor, MGM Institute of Physiotherapy Aurangabad. \\ Corresponding Author: Gayatri T. Batkulwar
}

\begin{abstract}
Background - Family members play important role in recovery of stroke patient. As stroke is a common, chronic condition with high morbidity, mortality and disability. The aim of study was to estimate stress level in family members of stroke patients.

Method - It was an observational study, done on 100 caregivers of stroke patients, by using PSS-10 scale to assess level of stress in family members. Online survey was done by making Google forms.

Result - 57\% of family members of stroke patient perceived moderate level of stress, this affects the mental health and quality of life of caregivers.

Conclusion - This study concludes that the stress was more in wives, sons, daughters in first relation whereas in second relation stress was more in daughter in law. Some interventions should be structured to reduce the level of stress in family members.
\end{abstract}

Key Words - Stress, stroke, caregivers, perceived, PSS.

\section{INTRODUCTION}

Stress can be defined as "a condition or feeling experienced when a person perceives that the demands placed on them exceeds the resources the individual has available." Stress can therefore be understood as a perceived imbalance between the demands encountered in daily living and a person's capability to respond.

Stress can affect all aspects of your life, including your emotions, behaviors, thinking ability and physical health. Prolonged stress is associated with poor physical and mental health outcomes ${ }^{2}$, and this can arouse feeling of fear, uselessness, anger, incompetence and guilt which ultimately results in headache, low energy, constant worrying, forgetfulness, inability to focus, poor judgements, depression, anxiety, personality disorders, etc.

Stroke (Cerebrovascular accident (CVA)) can be defined as sudden loss of neurological function caused by an interruption of blood flow to brain. ${ }^{3}$ Stroke is the second leading cause of death globally. ${ }^{4}$ The incidence of stroke increases with age, doubling after the age of 55 years. ${ }^{4}$ Stroke is a common chronic disease with high morbidity, mortality and disability in worldwide. $^{5}$

Like other disabling conditions the onset of the stroke is sudden, leaving individual and family ill prepared to deal with its consequences. ${ }^{6}$ Most people $(25 \%$ $50 \%$ ) with stroke are being cared for at home by family members. ${ }^{7}$ Giving care is stressful and family members are predisposed to care related complications such as life changes and perceives stress. ${ }^{7}$ Informal caregivers are defined as individuals who provide some type of unpaid ongoing assistance with activities of daily living or instrumental activities of daily living for individuals with a chronic illness or disability.8 Informal relatives (such as spouse, Husband, child) are 
backbone of services provided to surviving stroke patients. ${ }^{9}$

Informal caregivers play an important role in post stroke care, the stress factors amongst family members are as follows -

* Patients factors which are predictors for caregivers strain are as follows -

1) Severe disabilities such as hemiplegia, speech disability, facial drop, poor vision, etc

2) Poor cognition

3) Depression

4) Recurrent stroke ${ }^{10}$

* Caregivers factors which are associated with considerable caregivers strain are as follows -

1) Changed employment status

2) Help from formal caregivers

3) Anxiety, depression, stress ${ }^{10}$

At least $50-70 \%$ of stroke patients suffer from chronic neurological or cognitive impairment creating significant burden on patients' family. ${ }^{11}$ This makes patients and their families to fall into troubles of "adaptations" and "care" causes huge impact on mental health of caregivers. ${ }^{5}$ Caregivers stress is common and is caused by ongoing emotional and physical strain of caregiving. 8

It is reported that the main caregivers of stroke patients have an equal or greater incidence of having psychological issues such as increase in perceived stress, anxiety and depression, etc. ${ }^{5}$ This affects daily routine work and responsibilities of caregivers, this results in disturbance in emotional and physical state of the person. This is also a one of the reason of why psychological issues occur in the caregivers of stroke patients.

The rationale of this study was to identify the level of perceived stress among the family members of stroke patients and hence to help family members to tackle stress by perceiving different coping strategies and improve their personal life.

\section{METHODS AND METHODOLOGY}

This observational study was conducted in February - June 2021 on 100 family members of stroke patients, in Aurangabad city. Convenient sampling method was used for selecting the sample size. Participants in this study were selected according to the inclusion criteria. The data collection was done by online survey by making Google forms. The inclusion criteria included - main family members of stroke patients, both male and female family members of stroke patients, family members willing to participate in study, family members age between 18-50 yrs. Exclusion criteria were - Not willing to participate in the study, any paid caregiver, Family member who have diagnosed for any major medical condition.

\section{DIAGNOSTIC TOOL}

\section{1) Perceived stress scale (PSS-10)}

Perceived stress scale (PSS-10) was used to evaluate levels of stress. It is a brief and easy-to-use tool. It measures the degree to which situations in ones' life are appraised as stressful. It has been proven to possess substantial reliability and validity. The questions in this scale ask about the feelings and thoughts of the participants during the last one month. In each case, they will be asked to indicate how often they felt or thought a certain way. It is a 10 item questionnaire with responses in the form of how often they experienced certain situations from 0 - never to 4 - very often. ${ }^{12}$

\section{PROCEDURE:}

The purpose of the study was explained to the participants. This observational study was done on the family members of stroke patients. The participants were included in study on the basis of inclusion and exclusion criteria. The outcome measures Perceived Stress Scale were used.

Perceived stress scale is a measure of the degree to which situations in one's life are appraised as stressful. Items were designed to tap how unpredictable, 
uncontrollable, and overloaded respondents find their lives. It is brief and easy to administer tool. The scale includes questions about the feelings and thoughts of the individual during the last one month. It is a 10 item questionnaire with responses in the form of often they experience certain situation from 0 -never to 4-very often.

The scale and questionnaire were converted into Google form (http://play.google.com/store/apps/details?id =com.heartfull.forms) so it became convenient for participants to fill the form without any difficulty in the COVID-19 outbreak. Filled questionnaire and scales were collected in Google form responses and items were analysed for perceived stress level of the participants.

\section{RESULTS}

We conducted a study to find out the prevalence of perceived stress in family members of stroke patients. The present study had 100 caregivers (both male and female), with various relationships to the stroke patients, who responded to our questionnaire which was based on stress that they perceived. Most of the stroke survivors who are taken care at home, directly or indirectly places burden on the caregivers. Stroke patients have poor cognition, altered mood, decreased functional status and affected quality of life. The patient is dependent on his/her family members which results in burden on caregivers both economically $(80 \%)$ and mentally at individual and family level. As mentioned above, the questionnaire used in this study is perceived stress scale (PSS-10). This questionnaire contains four positive stated items and six negative stated items. The questions in this scale asks about the feelings and thoughts during the last month i.e. how often you felt or thought in a certain way.
Results depicted that moderate level of stress perceived in family members of stroke patients. Among 100 participant, $12 \%$ perceived low levels of stress, $57 \%$ perceived moderate levels of stress and $31 \%$ perceived high levels of stress (as shown in table no 1). As mentioned in our results, participants who participated in study were $50 \%$ males and $50 \%$ females, in that $10 \%$ male perceived low stress, $64 \%$ male perceived moderate stress and 26\% male perceived high level of stress where as $14 \%$ females perceived low stress, $50 \%$ females perceived moderate stress level and 36\% female caregiver perceived high stress levels (as shown in table no 2). Maximum number of relations we found in our study were wives, sons, daughter, daughter in law to stroke patients, who perceived moderate level of stress.

\begin{tabular}{|l|l|l|}
\multicolumn{4}{|c|}{ TABLE NO. 1 (PSS-10 Outcomes) } \\
\begin{tabular}{|l|l|l|}
\hline Stress level & Frequency & Percentage \\
\hline Low & 12 & $12 \%$ \\
\hline Moderate & 57 & $57 \%$ \\
\hline High & 31 & $31 \%$ \\
\hline
\end{tabular}
\end{tabular}

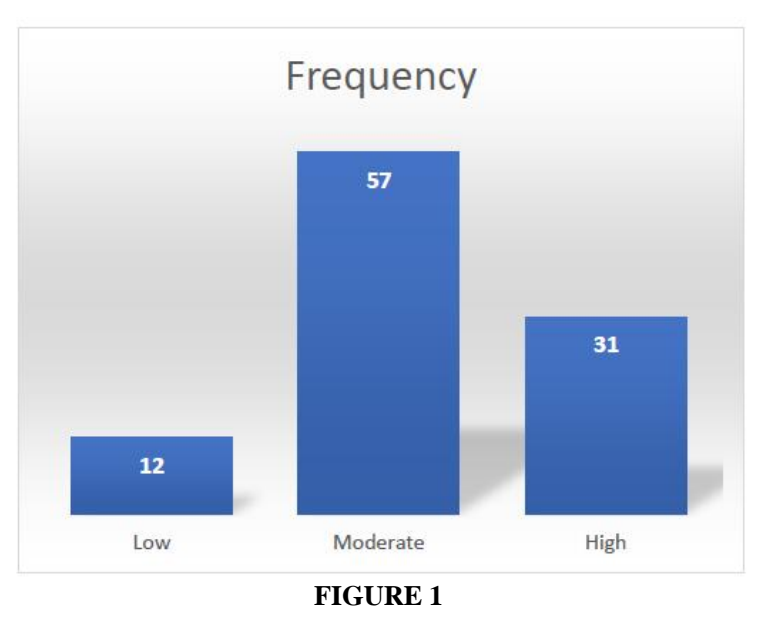

Above bar diagram, figure no.1 shows Perceived stress level among all caregivers. Among 100 caregivers 12\% perceived Low level of stress, $57 \%$ perceived Moderate level of stress and 31\% perceived High level of stress.

\begin{tabular}{|c|c|c|c|c|c|c|c|c|}
\hline \multirow[t]{3}{*}{ Gender of relatives } & \multicolumn{6}{|c|}{ Perceived stress level } & \multirow{2}{*}{\multicolumn{2}{|c|}{ Total }} \\
\hline & \multicolumn{2}{|c|}{ Low } & \multicolumn{2}{|c|}{ Moderate } & \multicolumn{2}{|c|}{ High } & & \\
\hline & No. & $\%$ & No. & $\%$ & No. & $\%$ & No. & $\%$ \\
\hline Male & 05 & 10 & 32 & 64 & 13 & 26 & 50 & 100 \\
\hline Female & 07 & 14 & 25 & 50 & 18 & 36 & 50 & 100 \\
\hline
\end{tabular}




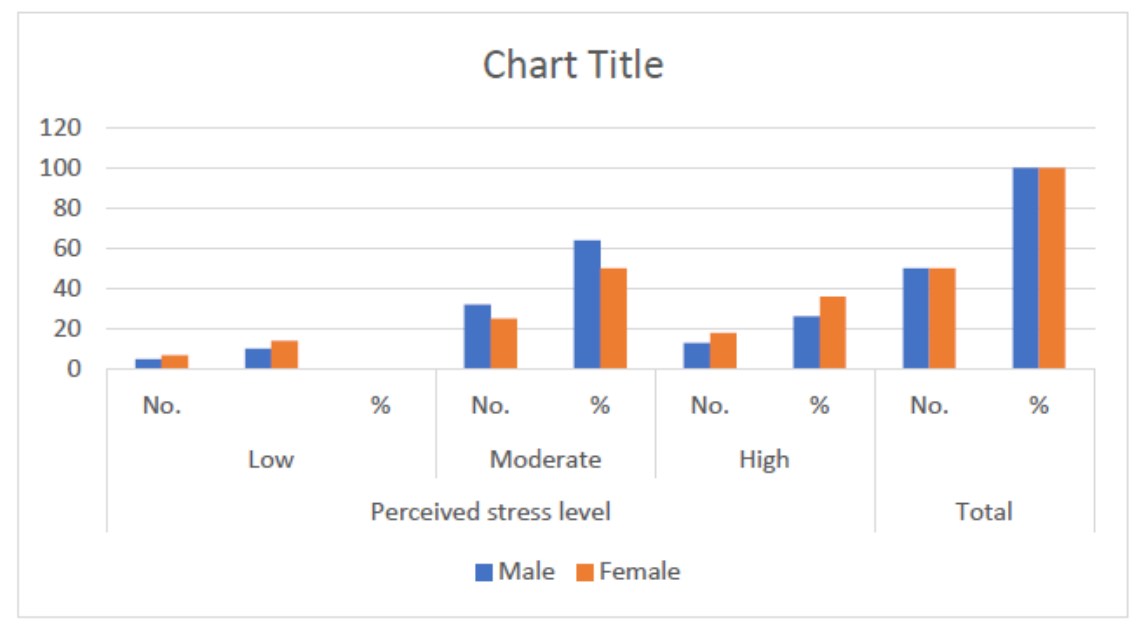

FIGURE 2

The above bar diagram, figure no. 2 shows perceived stress level in gender of relatives. In 50 male caregivers $-10 \%$ male caregiver perceived Low level of stress, $64 \%$ perceived Moderate level of stress and 26\% male caregivers perceived High level of stress and in 50 female caregivers $-14 \%$ perceived Low level of stress, $50 \%$ perceived Moderate level of stress and 36\% female caregiver perceived High level of stress.

\section{DISCUSSION}

This was an observational study done on family members of stroke patients. Around 100 family members participated in study. The results showed that $57 \%$ participants perceived moderate level of stress.

A study done on assessment of stress among caregivers of stroke survivors: community based study states that all caregivers participated in study were going through financial difficulties, physical strain, family and emotional adjustments and sleep disturbance were found to have contributed to their stress. So our study is concurrence with the study done by Babitha Rajan, Suman G, et al. In this study authors found that $88.7 \%$ caregivers were upset and $50.7 \%$ were feeling confined which is in accordance with our study where $94 \%$ caregivers found upset and $71 \%$ subjects thought they were not able to cope with all things that they had to do.
A study done on female caregivers and stroke severity determines caregiver stress in stroke patients, found that $90 \%$ caregivers were underwent in mood disturbances such as forgetfulness, sadness, confusion, anger, irritated. They concluded that caregiving burden was predominantly shouldered by female caregivers. So this research is in parallel to the current study where $62 \%$ and $66 \%$ caregivers thought that they were irritated and angered. ${ }^{13}$

A study performed on family functioning and depression in primary caregivers of stroke patients in china, found $\mathrm{SD}(2.12+-0.38)$ for behaviour control and $\mathrm{SD}(2.37+-0.30)$ for problem solving ability in stroke survivors family. They stated that it is necessary to improve the assessment of stroke survivor families and the effectiveness of family based interventions. ${ }^{11}$ Other than that, in current study $90 \%$ and $54 \%$ subjects thought that they were nervous and stressed and were confident about their ability to handle personal problems respectively.

The caregivers of stroke patients were undergoing in stress due to heavy responsibility, uncertainty of patients care needs, restraints in social life and feeling that patients entirely relies on their care. The financial difficulties can be increased if the stroke survivor is sole bread winner of family, the emotional disturbance can be occur due to the unexpected event which was happened in their life for which they 
were not prepared. So to lower the incidence of stress in family members of stroke patients proper interventions should be structured.

\section{CONCLUSION}

Our study showed that, caregivers perceived overall $57 \%$ moderate level of stress. The burden was more in wives, son, daughters and daughter in law. This influenced both personal life of caregivers and quality of care experienced by stroke survivor. This study suggests that some interventions should be structured to help caregivers cope with their perceived level of stress.

\section{Limitations}

1) The sample size is less, if the study can be done in large sample size then proper results can be find out.

2) The perceived stress scale (PSS-10) can be correlated with other scale, to know the level of limitation in caregivers.

3) In this study, online survey was done so personal interview with caregiver was not taken

\section{Acknowledgement: None}

\section{Conflict of Interest: None}

\section{Source of Funding: None}

\section{Ethical Approval: Approved}

\section{REFERENCES}

1. Heinen I, Bullinger M, Kocalevent RD. Perceived stress in first year medical students-associations with personal resources and emotional distress. BMC medical education. $2017 \mathrm{Dec} ; 17(1): 1-4$.

2. Liu S, Lithopoulos A, Zhang CQ, GarciaBarrera MA, Rhodes RE. Personality and perceived stress during COVID-19 pandemic: Testing the mediating role of perceived threat and efficacy. Personality and Individual differences. 2021 Jan 1;168:110351.
3. Susan B, O'Sullivan Thomas J. Schmitz. George D. Fulk,Physical Rehabilitation ,6th edition

4. Kuriakose D, Xiao Z. Pathophysiology and treatment of stroke: present status and future perspectives. International journal of molecular sciences. 2020 Jan;21(20):7609.

5. $\mathrm{Hu}$ P, Yang $\mathrm{Q}$, Kong $\mathrm{L}, \mathrm{Hu} \mathrm{L}$, Zeng $\mathrm{L}$. Relationship between the anxiety/depression and care burden of the major caregiver of stroke patients. Medicine. 2018 Oct;97(40).

6. Rajan B, Suman G, Pruthvish S, Radhika K. Assessment of stress among caregivers of the stroke survivors: community based study. International Journal of Community Medicine and Public Health. 2016;4(1):2115.

7. Peyrovi H, Mohammad-Saeid D, FarahaniNia M, Hoseini F. The relationship between perceived life changes and depression in caregivers of stroke patients. Journal of Neuroscience Nursing. 2012 Dec 1;44(6):329-36.

8. Kazemi A, Azimian J, Mafi M, Allen KA, Motalebi SA. Caregiver burden and coping strategies in caregivers of older patients with stroke. BMC psychology. 2021 Dec;9(1):1-9.

9. Ogunlana MO, Dada OO, Oyewo OS, Odole AC, Ogunsan MO. Quality of life and burden of informal caregivers of stroke survivors. Hong Kong Physiotherapy Journal. 2014 Jun 1;32(1):6-12.

10. Hung JW, Huang YC, Chen JH, Liao LN, Lin CJ, Chuo CY, Chang KC. Factors associated with strain in informal caregivers of stroke patients. Chang Gung Med J. 2012 Sep 1;35(5):392-401.

11. Guo YL, Liu YJ. Family functioning and depression in primary caregivers of stroke patients in China. International Journal of Nursing Sciences. 2015 Jun 1;2(2):184-9.

12. Cohen S, Kamarck T, Mermelstein R. Perceived stress scale. Measuring stress: A guide for health and social scientists. 1994;10(2):1-2.

13. Menon B, Salini P, Habeeba K, Conjeevaram J, Munisusmitha K. Female caregivers and stroke severity determines caregiver stress in stroke patients. Annals of Indian Academy of Neurology. 2017 Oct;20(4):418.

14. Em S, Bozkurt M, Caglayan M, Ceylan Cevik F, Kaya C, Oktayoglu P, Nas K. Psychological health of caregivers and 
association with functional status of stroke patients. Topics in stroke rehabilitation. 2017 Jul 4;24(5):323-9.

15. Efi P, Fani K, Eleni $T$, Stylianos K, Vassilios K, Konstantinos B, Chrysoula L, Kyriaki M. Quality of life and psychological distress of caregivers' of stroke people. Acta Neurol Taiwan. 2017 Dec 15;26(4):154-66.

16. Sutter-Leve R, Passint E, Ness D, Rindflesch A. The caregiver experience after stroke in a COVID-19 environment: a qualitative study in inpatient rehabilitation. Journal of Neurologic Physical Therapy. 2021 Jan;45(1):14.

17. Akosile CO, Banjo TO, Okoye EC, Ibikunle PO, Odole AC. Informal caregiving burden and perceived social support in an acute stroke care facility. Health and quality of life outcomes. 2018 Dec;16(1):1-7.
18. Byun E, Evans L, Sommers M, Tkacs N, Riegel B. Depressive symptoms in caregivers immediately after stroke. Topics in stroke rehabilitation. 2019 Apr 3;26(3): 187-94.

19. Long NX, Pinyopasakul W, Pongthavornkamol K, Panitrat R. Factors predicting the health status of caregivers of stroke survivors: A cross-sectional study. Nursing \& health sciences. 2019 Jun; 21(2):262-8.

How to cite this article: Batkulwar GT, Mhaske GC. Evaluation of perceived stress in family members of stroke patients. Int J Health Sci Res. 2021; 11(8): 131-136. DOI: https://doi.org/10. 52403/ijhsr.20210819 